\title{
Ein Beitrag zur Rezeption Heimito von Doderers in Tschechien
}

\author{
Heimito von Doderer's Reception in the Czech Republic
}

Veronika Horáčková

\begin{abstract}
This paper assesses the perception of the Austrian writer Heimito von Doderer (1896-1966) in the Czech Republic. Rather than focusing on the two Czech translations of his novels per se, it considers spin-offs such as academic theses and articles in the print media, as well as in the audio-visual media with a recording of Die Merowinger oder Die totale Familie.
\end{abstract}

\section{Keywords}

Heimito von Doderer; Die Merowinger; Austrian literature; Czech perception 
In diesem Beitrag beschäftige ich mich mit der Rezeption des österreichischen Schriftstellers Heimito von Doderer in Tschechien und in den tschechischen Landesteilen der Vorgängerstaaten ČSSR und ČSFR. Im Zentrum stehen dabei weniger die Übersetzungen seiner Romane ins Tschechische und damit verbundene Texte (wie etwa Rezensionen) - zu diesen (und den slowakischen Übersetzungen) ist bereits ein Beitrag von Jozef Tancer erschienen. ${ }^{1}$ Ich möchte daher andere Bereiche der Doderer-Rezeption in Tschechien erschließen, namentlich Enzyklopädien, Fachlexika, literaturwissenschaftliche Aufsätze, studentische Abschlussarbeiten sowie Zeitungs- und Zeitschriftenartikel, in denen von Doderer die Rede ist. Im Unterschied zu Tancer werde ich ausschließlich auf die Rezeption Doderers in Tschechien eingehen und jene in der Slowakei bzw. im slowakischen Landesteil von ČSSR und ČSFR außer Acht lassen. Im Anhang zu diesem Beitrag folgt eine Bibliographie der tschechischen Texte, die für die Rezeption Doderers in Tschechien relevant sind.

\section{Romanübersetzungen - Die Strudlhofstiege}

Die Rezeption Heimito von Doderers in Tschechien erscheint auf den ersten Blick nicht sehr beeindruckend. Derzeit liegen nur zwei seiner Romane in tschechischer Übersetzung vor: Die Merowinger und Die Wasserfälle von Slunj. Da diese Publikationen in Tancers Artikel ausführlich besprochen werden, möchte ich hier nur kurz auf sie eingehen. Die erste, nämlich Merovejci aneb totálni rodina (Die Merowinger oder Die totale Familie) erschien 1969 in der Übersetzung von Vilém Opatrný mit einem Nachwort des Verlagsredakteurs, Übersetzers und Germanisten Vladimír Kafka. ${ }^{2}$ Sechs Jahre später, 1975, folgte - übersetzt von der Germanistin Jitka Fuč́ková - Vodopád (Die Wasserfälle von Slunj) mit einem Nachwort des Übersetzers Hanuš Karlach, das den bezeichnenden Titel „Kronikář minulé epochy“ (Chronist der vergangenen Epoche) trägt. ${ }^{3}$

Nun hat jedoch der renommierte Academia Verlag, der 1953 als Publikationsort der Tschechoslowakischen Akademie der Wissenschaften gegründet wurde, eine tschechische Ausgabe der Strudlhofstiege unter dem Titel Strudlhofské schody angekündigt. Als Übersetzer konnte der Schriftsteller Ondřej Sekal gewonnen werden, der unter anderem Bücher von Joseph Roth übersetzt hat.

1 Vgl. Tancer, Jozef: Unter den Oplateks, Wewerkas und Zileks. Doderer in der Tschechoslowakei. In: Keime fundamentaler Irrtümer. Beiträge zu einer Wirkungsgeschichte Heimito von Doderers. Hrsg. v. Roland Innerhofer, Matthias Meyer u. Stefan Winterstein. Würzburg 2018 (Schriften der Heimito von Doderer-Gesellschaft; 10), S. 273-293.

2 Vgl. Doderer, Heimito von: Merovejci aneb Totální rodina. Übers. v. Vilém Opatrný. Praha 1969 bzw. Kafka, Vladimír: Doslov [Nachwort], ebd., S. 291-293; vgl. a. Tancer, Unter den Oplateks, Wewerkas und Zileks (Anm. 1), S. 278-281.

3 Vgl. Doderer, Heimito von: Vodopád. Übers. v. Jitka Fučíková. Praha 1975 bzw. Karlach, Hanuš: Kronikář minulé epochy, ebd., S. 341-347; vgl. a. Tancer, Unter den Oplateks, Wewerkas und Zileks (Anm. 1), S. 281-283. 


\section{Allgemeine Enzyklopädien}

Erstmals wurde Doderer, soweit feststellbar, in der Malá československá encyklopedie (Kleine tschechoslowakische Enzyklopädie; 1985) ein kurzer Artikel gewidmet, der sein Werk allgemein als das eines Chronisten der gesellschaftlichen Verhältnisse in Wien charakterisiert und drei seiner Romane nennt (Die Dämonen, Die Wasserfälle von Slunj und Die Merowinger). ${ }^{4}$

Etwas ausführlicher wurde hingegen in der V̌̌eobecná encyklopedie ve čtyrech svazcích (Allgemeine Enzyklopädie in vier Bänden; 1996) auf den Autor eingegangen. Doderer, so heißt es da, habe einen „grotesken, ironisierenden Stil“, seine Werke zeichneten sich durch eine komplizierte Komposition aus und würden beschreiben, wie Nationalsozialismus und Kommunismus die alten Sicherheiten zerstört hätten. Auch Die Strudlhofstiege wird fälschlich als „Strudelské schody“ (,Strudlstiege') übersetzt. ${ }^{5}$ Der gleiche Artikel wurde nochmals publiziert in Velký slovnik naučný (Das große Lehrwörterbuch; 1999). ${ }^{6}$

Schließlich findet sich noch ein sehr kurzer Artikel über Doderer in Ottova všeobecná encyklopedie ve dvou svazcich (Ottos allgemeine Enzyklopädie in zwei Bänden; 2003), in der drei seiner Romane erwähnt werden und sein Werk in einem einzigen Satz charakterisiert wird. ${ }^{7}$

Es fällt auf, dass in allen genannten Enzyklopädien stets dieselben Romane Doderers als Beispiele herangezogen werden, sein bekanntestes Werk, Die Strudlhofstiege, aber zugleich nur als (unzureichend übersetzter) Titel genannt wird. In später erschienenen Enzyklopädien wird Doderer lediglich unter anderen Lemmata erwähnt.

\section{Fachlexika, literaturwissenschaftliche Aufsätze und studentische Abschlussarbeiten}

Was Fachlexika betrifft, kann man Doderer in Slovnik spisovatelů německého jazyka a spisovateli lužickosrbských (Lexikon der Schriftsteller der deutschen Sprache und der sorbischen Schriftsteller; 1987) finden. Neben einer Übersicht über Leben und Werk erfährt man, dass der Autor sich von Sozialismus und Nationalsozialismus distanziert und dem Monarchismus nahegestanden habe, dass er - generell antirevolutionär eingestellt - jede Ideologie abgelehnt habe und also nicht auf der Seite des Proletariats zu verorten sei. Die Darstellung folgt sichtlich den ideologischen Vorgaben der damals noch im sozialistischen Lager stehenden Tschechoslowakei. ${ }^{8}$

4 Vgl. Malá československá encyklopedie. 6 Bde. Praha 1984-1987, Bd. 1: D-CH (1985), S. 148 („Doderer“).

5 Vgl. Všeobecná encyklopedie: ve čtyřech svazcích. 4 Bde. Praha 1996-1998, Bd. 1: A-F (1996), S. 531 („Doderer“).

6 Vgl. Velký slovník naučný. 2 Bde. Praha 1999, Bd. 1: A-L, S. 334 („Doderer“).

7 Vgl. Ottova všeobecná encyklopedie: ve dvou svazcích. 2 Bde. Praha 2003, Bd. 1: A-L, S. 283 („Doderer“).

8 Vgl. Bok, Václav / Macháčková-Riegerová, Věra / Veselý, Jiří: Slovník spisovatelů německého jazyka a spisovatelů lužickosrbských. Praha 1987, S. 190 f. 
Dem gegenüber steht das Lemma „Doderer“ in Slovnik světových literárnich dèl (Lexikon der Werke der Weltliteratur; 1988). In diesem Lexikon der schönen Literatur, das 1989 noch einmal herausgegeben wurde, wird der Roman Die Wasserfälle von Slunj besprochen. Nach einer Zusammenfassung des Inhalts werden Motive und Form des Buches analysiert. Anschließend werden weitere Werke des Autors erwähnt. Den Text beschließen ein illustrierender Satz aus dem Roman und bibliographische Angaben zur tschechischen Übersetzung. ${ }^{9}$

Dem Werk Doderers sind auch zwei Kapitel des Buches Studie a úvahy o německé literatuř (Studien und Erwägungen über die deutsche Literatur) gewidmet, dessen Autor der schon erwähnte Germanist Vladimír Kafka ist. Das erste, „Dodererova satira po rakousku“ (Doderers Satire auf österreichische Art) ${ }^{10}$ stammt aus Kafkas Nachlass, das zweite, „Merovejci aneb Totální rodina“ (Die Merowinger oder Die Totale Familie), ist identisch mit seinem Nachwort zur tschechischen Ausgabe der Merowinger. ${ }^{11}$

Erwähnenswert ist auch die Diplomarbeit von Monika Mikolášková, die an der Universität Budweis entstanden ist. Die Autorin widmet sich der Darstellung des Ersten Weltkriegs in der tschechischen und österreichischen Belletristik und erwähnt neben anderen Autoren auch Doderer. ${ }^{12}$ Sie konstatiert, dass die österreichischen Autoren die Beschreibung der ersten Jahrzehnte des 20. Jahrhunderts vermieden hätten, Doderer jedoch, was das betreffe, eine Ausnahme bilde. Mikolášková nennt in diesem Zusammenhang vor allem seine posthum erschienenen Erzählungen in dem Band Die sibirische Klarheit. Weiter geht sie auf Die Strudlhofstiege (auch sie nennt den Roman „Strudelské schody“) ein und erklärt, dass der Roman mit seinem einzigartigen Stil ein leicht provokatives, psychologisch genau durchdachtes literarisches Werk sei, ${ }^{13}$ das damals in Österreich ohne Entsprechung gewesen sei.

\section{Lehrbücher}

Doderer hat überraschenderweise auch Eingang in mehrere Lehrbücher gefunden. Besonders hervorzuheben ist der Band Německá literatura od pruni světové války (Deutsche Literatur seit dem Ersten Weltkrieg; 1965), der für Studenten der Philosophischen Fakultät der Palacký-Universität in Olomouc bestimmt war. Ludvík Václavek geht darin

9 Vgl. Macura, Vladimír: Slovník světových literárních děl. 2 Bde. Praha 1988, Bd. 1: A-L, S. 215 f. („Doderer“).

10 Vgl. Kafka, Vladimír: Dodererova satira po Rakousku. In: ders.: Studie a úvahy o německé literatuře. Praha 1995, S. 213 f. Tancer, Unter den Oplateks, Wewerkas und Zileks (Anm. 1), S. 279 übersetzt den Ausdruck „po rakousku“ als „durch Österreich“, bzw. „über Österreich“, weil er ihn „im räumlichen Sinne“, bzw. „im temporalen Sinne“ versteht. In der Überschrift des Textes steht „Österreich“ groß geschrieben, was Tancers Interpretation entspricht. An anderen Stellen des Buches (wie etwa im Inhaltsverzeichnis) wird es jedoch klein geschrieben. Darum vermute ich, dass damit eher die ,österreichische Art und Weise‘ gemeint ist.

11 Vgl. Kafka, Vladimír: Merovejci aneb Totální rodina. In: ders.: Studie a úvahy o německé literatuře (Anm. 10), S. 215-217 bzw. Kafka, Doslov (Anm. 2), S. 291-293.

12 Mikolášková, Monika: Beletristický obraz první světové války v české a rakouské literatuře. Phil. Dipl. Jihočeská univerzita v Českých Budějovicích, 2007, S. 31-33. https://theses.cz/id/x0hrqx/downloadPraceContent_adipIdno_4201 (12. 6. 2018).

13 Vgl. Mikolášková, Beletristický obraz první světové války v české a rakouské literatuře (Anm.12), S. 33. 
ausführlich auf Das Geheimnis des Reichs, Die Strudlhofstiege, Die erleuchteten Fenster, Die Dämonen, Die Merowinger, Die Wasserfälle von Slunj ein und ergänzend dazu auch auf Grundlagen und Funktion des Romans. Außerdem werden Motive und Themen angedeutet, die Doderer in den besprochenen Werken verarbeitet hat. ${ }^{14}$

Václavek hat fünf Jahre später auch Literatura v německém jazyce od počátků 20. století (Literatur in deutscher Sprache seit Anfang des 20. Jahrhunderts; 1970) herausgegeben. Der Text des zuvor genannten Buches wurde hierfür bearbeitet und erweitert. So wird nun auch kurz auf andere Werke Doderers (Gassen und Landschaft, Ein Mord, den jeder begeht und Unter schwarzen Sternen) eingegangen. ${ }^{15}$

Des Weiteren wird Doderer in einem Buch für (Gymnasial-)Schüler, Přehled maturitních témat a konverzačních témat ke státni zkoušce z německého jazyka (Übersicht der Abiturund Konversationsthemen zur Staatsprüfung in deutscher Sprache; 1996), als einer der Autoren der Wiener Dekadenz erwähnt. ${ }^{16}$ Schließlich erscheint Doderer in Rakousko (Österreich; 1989), das vom ,Institut für auswärtigen Handel ‘ herausgegeben wurde. In diesem Handbuch, das in der Reihe Vyspělé kapitalistické státy (Hochentwickelte kapitalistische Länder) erschienen ist, werden einmal mehr die drei bekannten Bücher Die Dämonen, Die Wasserfälle von Slunj und Die Merowinger als Beispiele genannt. ${ }^{17}$

\section{Erwähnungen an anderen Orten}

Erwähnungen Doderers finden sich auch in folgenden Publikationen:

Petr Mareš hat sich in seiner Untersuchung „Also nazdar!“ mit der Mehrsprachigkeit in der Literatur beschäftigt und dafür zahlreiche Werke der tschechischen Belletristik analysiert. Die tschechische Übersetzung der Wasserfälle von Slunj lieferte ihm ein Beispiel für den ebenso interessanten wie problematischen Sonderfall eines zielsprachlichen Satzes im Ausgangstext, der in der zielsprachlichen Ausgabe des Werkes seine Funktion nicht mehr erfüllen kann. ${ }^{18}$

Eine Erwähnung verdient auch das Deutsch-tschechische Wörterbuch der Phraseologismen und festgeprägten Wendungen, in dem die Wendung „ein Feschak sein“ anhand eines Zitats aus dem Roman Die Wasserfälle von Slunj belegt wird. ${ }^{19}$

14 Vgl. Václavek, Ludvík: Německá literatura od první světové války. Praha 1965, S. 239 f.

15 Vgl. Václavek, Ludvík: Literatura v německém jazyce od počátků 20. století. Praha 1970, S. 246 f.

16 Vavrečka, Petr: Přehled maturitních témat a konverzačních témat ke státní zkoušce z německého jazyka: (vypracovaná konverzační témata, reálie, základní literární přehled). Ostrava 1996, S. 111.

17 Filip, Jiří / Beránek, Jiří / Straka, Miloš: Rakousko. Praha 1989, S. 56.

18 Vgl. Mareš, Petr: „Also nazdar!“: aspekty textové vícejazyčnosti. Praha 2003 (Acta Universitatis Carolinae: Philologica: Monographia; 142), S. 33. Der fragliche Satz lautet: „,.... jste blázen?!‘ (Ob er verrückt geworden sei? - In der Erregung brach tschechischer Urlaut aus dem Knollengewächs.)“ Doderer, Heimito von: Die Wasserfälle von Slunj. München 1963, S. 86.

19 Vgl. Heřman, Karel / Blažejová, Markéta / Goldhahn, Helge: Deutsch-tschechisches Wörterbuch der Phraseologismen und festgeprägten Wendungen. 2 Bde. Praha 2010, Bd. 1: A-L, S. 555. 
Mit einem eher weniger bekannten Zitat über Komik und Ernsthaftigkeit in der Kunst ist Doderer auch in der Zitatensammlung Slovnik myšlenek (Ideenlexikon; 2003) vertreten..$^{20}$ Das Zitat stammt aus dem posthum erschienenen Tagebuchband Commentarii 1957 bis $1966^{21}$ und dürfte, da dieser auf Tschechisch nie erschienen ist, einer Rezension in der Zeitschrift Světová literatura (Weltliteratur) entnommen worden sein. ${ }^{22}$

Mehrmals wird Doderer auch im Essayband des tschechischen Philosophen Václav Bělohradský, Prírozený svět jako politický problém (Natürliche Welt als politisches Problem), genannt. ${ }^{23}$ Neben einigen isolierten Erwähnungen des Autors im Kapitel „Mitteleuropa: rakouská ŕíše jako metafora“ (Mitteleuropa: das österreichische Reich als Metapher) gibt es in diesem Essay zudem ein langes Zitat aus Die erleuchteten Fenster. ${ }^{24}$ Da der Roman nie ins Tschechische übersetzt wurde, arbeitete Bělohradský, der 1970 nach Italien emigrierte, mit der 1961 erschienenen italienischen Übersetzung. ${ }^{25}$

Interessant ist auch Doderers Erwähnung im Handbuch Model základního fondu krásné literatury pro veřejné knihovny (Grundbestandsmodell der schönen Literatur für öffentliche Bibliotheken), das nach der Revolution von der Nationalbibliothek in Prag herausgegeben wurde. Der Leitfaden nennt rund 1400 tschechische, slowakische und ausländische Autoren, deren Bücher in Bibliotheken nicht fehlen sollten, aber teilweise während der kommunistischen Herrschaft verboten waren. Von Doderer werden darin Die Merowinger als "groteske Satire eines österreichischen Autors“ empfohlen, die „Züge des Totalitarismus in der heutigen Welt enthüllt““. ${ }^{26}$

Eher abseitige Spuren hat Doderer in Mýtus Milena (Mythos Milena) hinterlassen, in dem Leben und Werk der tschechischen Journalistin und Schriftstellerin Milena Jesenská dargestellt werden. Jesenská, einem größeren Publikum vor allem als Freundin Franz Kafkas bekannt, war die erste Ehefrau des Literaturkritikers Ernst Pollak, der wiederum - 1923 - der Geliebte der Schwester von Doderers damaliger Freundin und späterer erster Ehefrau Gusti Hasterlik wurde. Zudem heißt es in Mýtus Milena, der Schriftsteller und Übersetzer Graf Franz Xaver Schaffgotsch, später seinerseits Geliebter von Jesenská und mit Doderer befreundet, sei dafür verantwortlich gewesen, dass der Autor aus der Kriegsgefangenschaft in der Sowjetunion nach Wien zurückkehrte. ${ }^{27}$ Schließ-

20 Ševčíková, Hana: Slovník myšlenek. Olomouc 2003, S. 105.

21 Vgl. Doderer, Heimito von: Commentarii 1957 bis 1966. Tagebücher aus dem Nachlaß. Zweiter Band. Hrsg. v. Wendelin Schmidt-Dengler. München 1986, S. 253 (23. September 1960).

22 Vgl. Veselý, Jiří: Glosy k vlastnímu dílu. In: Světová literatura: revue zahraničních literatur 34 (1989), H. 2 , S. 240 f. bzw. Anm. 32.

23 Vgl. Bělohradský, Václav: Mitteleuropa: rakouská říše jako metafora. In: ders.: Přirozený svět jako politický problém: (eseje o člověku pozdní doby). Praha 1991, S. 39-60.

24 Vgl. Bělohradský, Mitteleuropa: rakouská ř́še jako metafora (Anm. 23), S. 44 f.

25 Doderer, Heimito von: Le finestre illuminate ovvero Come il consigliere Julius Zihal divenne uomo. Torino 1961 (I coralli; 137).

26 Haman, Aleš: Model základního fondu krásné literatury pro veřejné knihovny. Praha 1990. S. 83.

27 Marková-Kotyková, Marta: Mýtus Milena: Milena Jesenská jinak. Praha 1993, S. 31. Die Behauptung ist insofern zutreffend, als Schaffgotsch im Auftrag des dänischen Roten Kreuzes die Betreuung der aus Österreich-Ungarn stammenden Kriegsgefangenen in russischen Lagern übernommen hatte (vgl. Fleischer, Wolfgang: Das verleugnete Leben. Die Biographie des Heimito von Doderer. Wien 1996, S. 92). 
lich kann man in Mýtus Milena nachlesen, wie Doderer Pollaks Begeisterung für Kafka kommentierte: „Lazar, Storfer, Grüner, E. Pollak, heute tot oder in der Welt zerstreut, trieben dort [im Wiener Café Central] ihren Kafka-Kult.“"28

Auf ein Doderer-Zitat stößt man auch in einer Nummer der Zeitschrift 100+1 zahranični zajimavost $\left(100+1\right.$ ausländische Merkwürdigkeit) aus dem Jahre $1964 .{ }^{29}$ Das heute noch erscheinende Magazin war zu Zeiten der ČSSR eine wichtige Informationsquelle für das Leben im kapitalistischen Ausland. In einem leicht satirischen Text wird behauptet, dass Ruhm und Bedeutung Wiens Geschichte seien, und dies damit belegt, dass die österreichische Zeitung Die Presse folgende Rundfrage gestellt hätte: „Warum ist Wien langweilig?“ Doderers Antwort darauf sei gewesen: „Der Stadt fehlten messerscharfe kritische Institutionen auf dem Gebiet der Literatur und Presse.“30

Gleich mehrfach erwähnt wurde Doderer in der Zeitschrift Světová literatura (Die Weltliteratur). Im fünften Heft des Jahres 1958 gibt es einen Aufsatz über moderne österreichische Literatur von Leopold Grünwald, in dem eine Passage Doderer und seinem Werk gewidmet ist. Die Strudlhofstiege wird darin allerdings sehr merkwürdig mit „Zadní točité schodiště“ (,Hinterwendeltreppe') übersetzt. ${ }^{31}$

Die vielleicht wichtigste Erwähnung Doderers in Světová literatura findet sich im zweiten Heft des Jahres 1989 in einer Rezension des Übersetzers Jiří Veselý, die „Glosy k vlastnímu dílu“ (Glossen zum eigenen Werk) heißt. Sie befasst sich mit Doderers posthum erschienenen Tagebüchern Commentarii 1951 bis 1956 und Commentarii 1957 bis 1966 . Veselý konstatiert, Doderer habe sich in seinen Tagebüchern kaum je spontan über Persönliches geäußert, sondern vor allem sein Schreiben kommentiert, was eher für Literaturwissenschaftler von Belang sei. Zudem moniert er, dass die Ausgabe der Tagebücher von der Persönlichkeit des Editors beeinflusst und daher nicht ganz objektiv sei. ${ }^{32}$

\section{Die Rundfunk-Lesung der Merowinger}

Sein größtes Publikum erreichte Doderer in Tschechien wahrscheinlich 1997 mit der Ausstrahlung einer Einlesung der tschechischen Fassung seines Romans Die Merowinger durch den öffentlich-rechtlichen Sender Český rozhlas Vltava, der vor allem auf klassische Musik und Hörspiele spezialisiert ist. Die Lesung wurde in zwölf etwa halbstündigen

28 Marková-Kotyková, Mýtus Milena (Anm. 27), S. 53. Es dürfte sich hier allerdings nicht um einen authentischen Kommentar Doderers aus den 20er Jahren, sondern um eine rückblickende Aussage des Autors handeln; vgl. Doderer, Heimito von: Nicht alle zogen nach Berlin. In: Magnum 9 (1961), H. 35, S. 53 f., hier: S. 53 (Hinweis: Gerald Sommer).

29 Vgl. 100+1 zahraniční zajímavost 1 (1964), H. 20, S. 3.

30 Rundfrage und Zitat wurden übernommen aus: [Anon.]: Die Königin nimmt ab. In: Der Spiegel (9. 9. 1964), S. 83-85, hier S. 84.

31 Vgl. Grünwald, Leopold: Moderní rakouská literatura. In: Světová literatura: revue zahraničních literatur 3 (1958), H. 5, S. 179-195, hier S. 187.

32 Vgl. Veselý, Glosy k vlastnímu dílu (Anm. 22), S. 240 f. 
Folgen im Rahmen der Sendung Četba (Lektüre) gesendet. Die erste wurde am 22. September 1997 ausgestrahlt, die weiteren an den folgenden Tagen, jeweils um 18:30. ${ }^{33}$

Die Aufnahme basierte auf einer von Drahomíra Vohnoutová und Dana Valtrová vorgenommenen Bearbeitung der 1969 erschienenen Übersetzung Vilém Opatrnýs. Als Leser wurde der Schauspieler Lukáš Hlavica verpflichtet, die Regie übernahm Petr Adler, die zuständige Redakteurin war Blanka Stárková. ${ }^{34}$

In der ersten Folge weicht die Aufnahme nur wenig vom publizierten Text ab: Wortfolgen werden verändert, damit sie natürlicher klingen, Wörter leicht modifiziert, damit sie sich besser sprechen lassen, Wörter, Sätze und sogar Absätze, die für das Verständnis nicht wichtig sind, ganz ausgelassen. Einige Wörter, die im übersetzten Text fehlen, aber für die Satzlogik notwendig sind, wurden hingegen ergänzt.

Auf Grundlage der ersten Folge wäre also zu erwarten, dass die ausgestrahlte Lesung sowohl den Inhalt als auch die Form des Textes respektiert. Kleine Modifikationen und/oder das Weglassen einzelner Wörter und Passagen dürften den Text als Ganzen kaum beeinträchtigen. Die Hörer der Rundfunk-Lesung sollten Die Merowinger folglich annähernd in gleicher Weise rezipieren können wie die Leser der Buchausgabe. Da die Rundfunk-Lesung nur rund 360 Minuten dauert, ist jedoch davon auszugehen, dass der Text der Buchausgabe in den weiteren Folgen stark gekürzt wiedergegeben wird - zum Vergleich: Die Hörbuchfassung der deutschen Ausgabe der Merowinger hat eine Lesezeit von etwa 740 Minuten..$^{35}$ Die erste Folge kann daher nicht als repräsentativ für die gesamte Rundfunk-Lesung angesehen werden, sodass die oben vorgestellten Annahmen nach Prüfung aller Folgen (zum Zeitpunkt der Niederschrift dieses Beitrags lag der Verfasserin leider nur ein privat gemachter Mitschnitt der ersten Folge vor) sehr wahrscheinlich zu revidieren wären.

\section{Fazit}

Die Rezeption Doderers in Tschechien ist nicht nur auf die beiden Romane beschränkt, die in Übersetzung vorliegen. Der Autor ist überdies in einigen älteren Enzyklopädien, in Lehrbüchern, literaturwissenschaftlichen und -kritischen Publikationen, aber auch in Zeitschriften, Zeitungen und Büchern unterschiedlicher Genres präsent. Als Besonderheit hervorzuheben ist, dass Autor und Werk in Tschechien aufgrund der Rundfunk-Lesung der tschechischen Fassung der Merowinger nicht nur in den Printmedien Verbreitung gefunden haben. Dass Doderer in Tschechien nach wie vor gegenwärtig ist, beweist schließlich auch die Ankündigung einer tschechischen Ausgabe der Strudlhofstiege.

33 Vgl. dazu den Programmhinweis in Práce. Český deník v českých rukou (Praha), 22. 9. 1997, S. 12 sowie die schriftliche Auskunft von Martina Němcová, Assistentin des Senders Český rozhlas Vltava, gegenüber der Verfasserin vom 14. Juni 2018.

34 Vgl. dazu die schriftliche Auskunft von Martina Němcová (Anm. 33).

35 Vgl. Doderer, Heimito von: Die Merowinger oder Die totale Familie. Gelesen von Bernd Jeschek. 10 CDs. Wien 2006. 


\section{Literaturverzeichnis}

[ANON.] (1964): [Doderer-Zitat]. In: 100+1 zahraniční zajímavost 1 (1964), H. 20, S. 3.

[ANON.] (1964): Die Königin nimmt ab. In: Der Spiegel (Hamburg), 9. 9. 1964, S. 83-85.

[ANON.] (1997): [Programmhinweis]. In: Práce. Český deník v českých rukou (Praha), 22. 9. 1997.

BĚLOHRADSKÝ, Václav (1991): Mitteleuropa: rakouská říše jako metafora. In: ders.: Přirozený svět jako politický problém: (eseje o člověku pozdní doby). Praha, S. 39-60.

BOK, Václav / MACHÁČKOVÁ-RIEGEROVÁ, Věra / VESELÝ, Jiří (1987): Slovník spisovatelů německého jazyka a spisovatelů lužickosrbských. Praha, S. 190 f.

DODERER, Heimito von (1961): Le finestre illuminate ovvero Come il consigliere Julius Zihal divenne uomo. Torino (I coralli; 137).

DODERER, Heimito von (1961): Nicht alle zogen nach Berlin. In: Magnum 9 (1961), H. 35, S. 53 f.

DODERER, Heimito von (1963): Die Wasserfälle von Slunj. München.

DODERER, Heimito von (1986): Commentarii 1957 bis 1966. Tagebücher aus dem Nachlaß. Zweiter Band. Hrsg. v. Wendelin Schmidt-Dengler. München.

DODERER, Heimito von (2006): Die Merowinger oder Die totale Familie. Gelesen von Bernd Jeschek. 10 CDs. Wien.

FILIP, Jiří / BERÁNEK, Jiří / STRAKA, Miloš (1989): Rakousko. Praha.

FLEISCHER, Wolfgang (1996): Das verleugnete Leben. Die Biographie des Heimito von Doderer. Wien.

GRÜNWALD, Leopold (1958): Moderní rakouská literatura. In: Světová literatura: revue zahraničních literatur. Státní nakladatelství krásné literatury, hudby a umění 3 (1958), H. 5, S. 179-195.

HAMAN, Aleš (1990): Model základního fondu krásné literatury pro veřejné knihovny. Praha, S. 83.

HĚ̌MAN, Karel / BLAŽEJOVÁ, Markéta / GOLDHAHN, Helge (2010): Deutsch-tschechisches Wörterbuch der Phraseologismen und festgeprägten Wendungen. 2 Bde. Praha, Bd. 1: A-L.

MACURA, Vladimír (1988): Slovník světových literárních děl. 2 Bde. Praha, Bd. 1: A-L, S. 215 f. („Doderer“).

MALÁ ČESKOSLOVENSKÁ ENCYKLOPEDIE (1985): 6 Bde. Praha 1984-1987, Bd. 1: D-CH, S. 148 („Doderer“).

MAREŠ, Petr (2003): „Also nazdar!“: aspekty textové vícejazyčnosti. Praha (Acta Universitatis Carolinae: Philologica: Monographia; 142).

MARKOVÁ-KOTYKOVÁ, Marta (1993): Mýtus Milena: Milena Jesenská jinak. Praha, S. 31 u. 53.

OTTOVA VŠEOBECNÁ ENCYKLOPEDIE: VE DVOU SVAZCÍCH (2003): 2 Bde. Praha, Bd. 1: A-L, S. 283 („Doderer“).

ŠEVČí́KOVÁ, Hana (2003): Slovník myšlenek. Olomouc.

VÁCLAVEK, Ludvík (1965): Německá literatura od první světové války. Praha, S. 239 f.

VÁCLAVEK, Ludvík (1970): Literatura v německém jazyce od počátků 20. století. Praha, S. 246 f.

VAVREČKA, Petr (1996): Přehled maturitních témat a konverzačních témat ke státní zkoušce z německého jazyka: (vypracovaná konverzační témata, reálie, základní literární přehled). Ostrava.

VELKÝ SLOVNÍK NAUČNÝ (1999): 2 Bde. Praha 1999, Bd. 1: A-L, S. 334 („Doderer“).

VESELÝ, Jiří (1989): Glosy k vlastnímu dílu. In: Světová literatura: revue zahraničních literatur. 34 (1989) H. 2, S. 240 f.

VŠEOBECNÁ ENCYKLOPEDIE: VE ČTYŘECH SVAZCÍCH (1996): 4 Bde. Praha 1996-1998, Bd. 1: A-F, S. 531 („Doderer“). 
Mgr. Veronika Horáčková / 399625@mail.muni.cz

Masarykova univerzita, Filozofická fakulta,

Ústav germanistiky, nordistiky a nederlandistiky,

Arna Nováka 1, 60200 Brno, CZ 


\section{Bibliographie zur Rezeption Heimito von Doderers in Tschechien}

Veronika Horáčková

\section{Übersetzungen}

DODERER, Heimito von (1969): Merovejci aneb totální rodina. Z německého originálu přeložil Vilém Opatrný. Doslov napsal Vladimír Kafka. Praha.

DODERER, Heimito von (1975): Vodopád. Z německého originálu přeložil Jitka Fučíková. Doslov napsal Hanuš Karlach. Praha (Soudobá světová próza; 309).

\section{Einlesungen}

DODERER, Heimito von (1969): Poslední dobrodružství [Das letzte Abenteuer]. In: Moderní próza, 20. 2. 1969 (Český rozhlas Praha) [nachträglich ermittelt].

DODERER, Heimito von (1997): Merovejci aneb totální rodina. In: Četba, ab 22. 9. 1997 [in 12 Folgen] (Český rozhlas Vltava).

\section{Literaturwissenschaftliche Arbeiten}

KAFKA, Vladimír (1969/1995): Doslov. In: Heimito von Doderer: Merovejci aneb Totální rodina. Z německého originálu přeložil Vilém Opatrný. Doslov napsal Vladimír Kafka. Praha, S. 291293; wieder als: Merovejci aneb Totální rodina (Heimito von Doderer). In: ders.: Studie a úvahy o německé literatuře. Praha, S. 215-217.

KAFKA, Vladimír (1995): Dodererova satira po Rakousku. In: ders.: Studie a úvahy o německé literatuře. Praha, S. 213 f.

KARLACH, Hanuš (1975): Kronikář minulé epochy. In: Heimito von Doderer: Vodopád. Z německého originálu přeložil Jitka Fučíková. Doslov napsal Hanuš Karlach. Praha (Soudobá světová próza; 309), S. 341-347.

MIKOLÁŠKOVÁ, Monika (2007): Beletristický obraz první světové války v české a rakouské literatuře. Phil. Dipl. Jihočeská univerzita v Českých Budějovicích, S. 31-33.

TANCER, Jozef (2018): Unter den Oplateks, Wewerkas und Zileks. Doderer in der Tschechoslowakei. In: Keime fundamentaler Irrtümer. Beiträge zu einer Wirkungsgeschichte Heimito von Doderers. Hrsg. v. Roland Innerhofer, Matthias Meyer u. Stefan Winterstein. Würzburg (Schriften der Heimito von Doderer-Gesellschaft; 10), S. 273-293.

VÁCLAVEK, Ludvík (1965): Německá literatura od první světové války. Praha, S. 239 f.

VÁCLAVEK, Ludvík (1970): Literatura v německém jazyce od počátků 20. století. Praha, S. 246 f. 


\section{Lexikonartikel}

BOK, Václav / MACHÁČKOVÁ-RIEGEROVÁ, Věra / VESELÝ, Jiří (1987): Slovník spisovatelů německého jazyka a spisovatelů lužickosrbských. Praha, S. 190 f.

MACURA, Vladimír (1988): Slovník světových literárních děl. 2 Bde. Praha, Bd. 1: A-L, S. 215 f. („Doderer“).

MALÁ ČESKOSLOVENSKÁ ENCYKLOPEDIE (1985): 6 Bde. Praha 1984-1987, Bd. 1: D-CH, S. 148 („Doderer“).

OTTOVA VŠEOBECNÁ ENCYKLOPEDIE: VE DVOU SVAZCÍCH (2003): 2 Bde. Praha, Bd. 1: A-L, S. 283 („Doderer“).

VELKÝ SLOVNÍK NAUČNÝ (1999): 2 Bde. Praha 1999, Bd. 1: A-L, S. 334 („Doderer“).

VŠEOBECNÁ ENCYKLOPEDIE: VE ČTYŘECH SVAZCÍCH (1996): 4 Bde. Praha 1996-1998, Bd. 1: A-F, S. 531 („Doderer“).

\section{Hinweise auf Neuerscheinungen / Besprechungen von Merovejci aneb totální rodina (1969) und Vodopád (1975)}

[ANON.] (1969): [Neuerscheinungen]. In: Knižní novinky 5 (1969), H. 4, S. 83.

[ANON.] (1969): Př́̌ští týden vyjde. In: Nové knihy, 13. 8. 1969, S. 3.

[ANON.] (1969): V prodeji tento týden. In: Nové knihy, 20. 8. 1969, S. 2.

[ANON.] (1975): Knihy zaslané redakci. In: Literární měsíčník 4 (1975), H. 7, S. 128.

[ANON.] (1975): Chystané knihy. In: Nové knihy, 16. 7. 1975, S. 3.

[ANON.] (1975): Vydané knihy. In: Nové knihy, 23. 7. 1975, S. 2.

-HK- (1975): Dodererův Vodopád. In: Nové knihy, 23. 7. 1975, S. 4.

-HK- (1975): Vodopád. Přírodní skutečnost a symbol. In: Novinky Odeonu jaro / 1975, S. 19.

VESELÝ, Jiří (1989): Glosy k vlastnímu dílu. In: Světová literatura: revue zahraničních literatur 34 (1989) H. 2, S. $240 \mathrm{f}$.

\section{Programmhinweise zu den Einlesungen von Poslední dobrodružství (1969) und Merovejci aneb totální rodina (1997)}

[ANON.] (1969): Co v rozhlase. In: Čtenář. Měsíčník pro práci s knihou 21 (1969), H. 20, S. 38. [ANON.] (1997): [Programmhinweis]. In: Práce. Český deník v českých rukou (Praha), 22. 9. 1997.

\section{Sonstige Erwähnungen}

[ANON.] (1964): [Doderer-Zitat]. In: 100+1 zahraniční zajímavost 1 (1964), H. 20, S. 3.

[ANON.] (1969): Ediční plán nakladatelství Mladá fronta na rok 1969 [Černá řada soudobé světové prózy]. In: Nové knihy, 8. 1. 1969 (Beilage).

GRÜNWALD, Leopold (1958): Moderní rakouská literatura. In: Světová literatura: revue zahraničních literatur. Státní nakladatelství krásné literatury, hudby a umění 3 (1958), H. 5, S. 179-195.

HAMAN, Aleš (1990): Model základního fondu krásné literatury pro veřejné knihovny. Praha, S. 83.

MARKOVÁ-KOTYKOVÁ, Marta (1993): Mýtus Milena: Milena Jesenská jinak. Praha, S. 31 u. 53. 